\title{
Una nueva traducción de las Confesiones de San Agustín
}

El sino de las obras maestras del pasado es estar siempre siendo traducidas de nuevo. No sólo porque la lengua evoluciona, sino también porque quien la lee en su lengua original tiene con frecuencia la sensación de que las traducciones ya existentes no han acertado a trasmitir debidamente la riqueza del texto, o porque se piensa en un determinado público o, incluso, por razones puramente comerciales. Las Confesiones de san Agustín, lejos de representar una excepción, son la mejor confirmación de lo que acabamos de decir. Muchas son ya las traducciones que circulan de venta en las librerías. Pero ello no obsta para que periódicamente aparezcan otras nuevas. Entre ellas la que presentamos:

San Agustín, Las Confesiones. Traducción, introducción, notas y anexo de Agustín Uña Juárez. Tecnos, Madrid 2006, 20,5 x 12, 560 pp.

Su autor, Agustín Uña Juárez, se mueve en el mundo de la filosofía. Y eso deja su huella en la obra. Primero en la intención y luego en la realización. En la intención, en cuanto que su traducción nace con vocación de manual universitario, a la vez que como obra de divulgación cultural, por lo que pretende ofrecer «un texto de garantía por su base técnica y claro en su ejecución». En la realización, porque a ese objetivo quiere que sirvan la introducción general, con su bibliografía selecta, y otras características de la obra. Las dos primeras partes de la amplia introducción (pp. 31-109) versan, respectivamente, sobre el Agustín de las Confesiones (un esquema básico de su vida, el contexto familiar y momento histórico, y su perfil humano) y las Confesiones de Agustín (noción de confessio, unidad $y$ estructura de las Confesiones, $y$ lenguaje y estilo de la obra). El autor co- 
noce la bibliografía y hace uso de ella en un marco propio, es decir, sin limitarse a un simple repetir lo que otros han dicho, y con claridad de exposición.

Para ayudar al lector, A. U. J. ofrece al principio y al final de los distintos libros sendas notas en las que pone de relieve lo que cada uno representa de específico en el conjunto de la obra, así como una pequeña síntesis del contenido material, acompañada de las oportunas referencias bibliográficas. Diferencia esta edición de las demás el introducir dentro del texto, a continuación de determinados capítulos, aunque con un cuerpo de letra menor y precedidas de asterisco para distinguirlas del texto agustiniano, notas explicativas. Más en los primeros libros y menos a medida que avanza la obra. En ellas reseña los aspectos que le parecen significativos o más reveladores del ser, pensar, método y, a veces, expresión de Agustín, siguiendo paso a paso una «clarificación sistemática de la experiencia subjetiva del yo en sus diversas situaciones y acciones» (p. 278). Todo a tono con dos modos de presentar la obra maestra agustiniana: como «una magna espeleología de la interioridad humana» (p. 133) y como una «práctica y teoría de la identidad del yo» (p. 399). A pie de página lleva otras notas, la mayor parte de las cuales contienen algunas de las muchas referencias bíblicas que inundan el texto y, ocasionalmente, aclaraciones de diverso signo. En un anexo final ofrece un índice onomástico y topográfico del texto de las Confesiones. Mantiene la división tradicional en libros, capítulos y parágrafos, aunque en un caso se aparta un poco (el último punto de 13,18,22, lo pasa al parágrafo 23). A cada capítulo le precede un epígrafe del traductor. A la fácil consulta de la obra contribuye el que cada página lleve indicado en el encabezamiento libro, capítulo y parágrafo.

En la tercera parte de la introducción (pp. 109-114) el autor presenta su traducción de la obra completa. El texto latino seguido se basa en las tres ediciones más solventes en la actualidad (la de Skutella, la de Verheijen y la de O'Donnell). Su trabajo lo presiden tres ideales: fidelidad al texto como compromiso con el autor, y precisión de lenguaje y belleza expresiva, es decir, expresión fluida y bella, como compromiso con el lector. Ese ideal ha pretendido hacerlo realidad mediante un estudio frase por frase, capítulo a capítulo. «Y siendo el de Agustín lenguaje depurado, y su obra de muy selecta cultura, se intenta evitar la vulgaridad a toda costa. Buscar un texto de garantía, un instrumento válido de comprensión, de sonido fluido, pone en juego el sentido de la lengua latina, el sentido de la lengua propia y el sentido común». A. U. J. juzga que el texto que ofrece a 
los lectores es «un texto ponderado y contrastado. El trabajo ha sido grande, pero el afecto por la obra, mayor. Confiemos en que se pueda notar». Su declaración de intenciones va todavía más allá: «Entre la fidelidad servil y la modernización despiadada e incolora, se ha intentado captar el sabor originario y personal del lenguaje de Agustín». Y confía en que esto se note también. Reconoce la existencia de límites, pues el retórico Agustín se hace presente «en frases complejas, delicias en sus días y dureza en los nuestros», produciendo pasajes en los que el discurso no «corre». En esos casos, donde era posible sin alterar su sentido originario, ha optado por «trocear» los interminables períodos para poder entenderlos al compás de su lectura. El traductor detecta esta ley: «cuando el discurso oratorio se extrema, la expresión española no corre. Y, si se trata de maniqueos, se hace oscuridad». Juzga criterio objetivo de claridad el «disciplinar el orden de las palabras dentro de cada frase, es decir, considerar las funciones sintácticas y las conexiones de sentido entre ellas para colocarlas». Y cree haber cuidado ese particular. Toma nota también de que las frases de Agustín presentan cierta rotundidad o cierta plenitud de significado en su sonido, sobre todo en su final, juego vital en los usos lingüísticos de Agustín. El traductor ha intentado no pocas veces revivir ese tono o matiz de la lengua del Santo. Por último, pide disculpa de antemano por las faltas y pequeños errores que no se agotan tras mil lecturas y que lamenta. Pues es su deseo facilitar a todos una lectura provechosa, de fácil contacto con el genio de Hipona.

Hasta aquí la presentación que de su obra hace el traductor; lo que viene a continuación es la apreciación de este lector.

Antes de entrar en harina, digamos que hemos leído la traducción con el texto latino delante. Pero el texto latino sólo lo hemos consultado cuando algo nos resultaba extraño en nuestra lectura. No hemos realizado, pues, una confrontación sistemática y completa con el texto original. El resultado hay que considerarlo, por tanto, parcial. Asimismo, la confrontación tiene algo de problemática porque el traductor indica en qué ediciones críticas se inspira, pero la edición no ofrece el texto latino. Esto puede significar que, en algún caso, nuestra apreciación tenga en su origen una diversa lectura en el texto original. Nuestra valoración se divide en dos partes. Siguiendo al traductor, valoramos primero el compromiso con el autor y luego el compromiso con el lector.

A. El compromiso con el autor: la fidelidad. El traductor se propuso como objetivo no sucumbir a la fidelidad servil. Pero, aunque no lo sea 
con referencia a la expresión, esta fidelidad servil es meritoria referida al contenido. La tarea del traductor puede compararse a la de una persona que trata de trasvasar un líquido de un recipiente a otro. En el caso, sólo el recipiente es diferente; el líquido ha de ser exactamente el mismo. Aunque es inevitable que en el trasvase se pierda algo, el esfuerzo hay que dirigirlo a que sea lo menos posible. La impresión de este lector de la obra presentada es que en el trasvase se ha perdido bastante más de esa cantidad inevitable. El juicio lo fundamentamos en los datos que siguen a continuación.

1) Hemos detectado lagunas, no todas del mismo alcance, en el texto de la traducción, es decir, palabras, sintagmas o frases que no aparecen traducidas (es lo que va en cursiva): tantis peccatorum $(2,7,15)$; resuscitandum tibi $(6,1,1)$; unius veri et veracissimi $(6,5,7)$; omnia phantasmata $(7,1,1)$; os meum $(7,8,11)$; grando, nix $(7,13,19)$; cum tu aeternum tibi $(8,3,8)$; et concordiae suorum consulens $(9,9,20)$; quaedam miseria $(9,12,29)$; filiorum hominum $(10,4,6)$; in filiis $(10,34,51)$; rerum motibus... nullum verum tempus totum esse praesens $(11,11,13)$; et ecce Spiritus tus superferebatur super aquas $(13,5,6)$; no la hubiera... (13,10,11); semper legunt et numquam praeterit quod legunt $(13,15,18)$.

2) Asimismo la traducción introduce términos que no están en el original y que, a veces, cambian el sentido de la frase: me dabas $t u$ ciencia $(1,15,24)$; siendo yo ya fácil de seducir $(2,3,8)$; me veía en su predicación $(6,2,2)$; de tus misterios $(6,5,8)$; la luz de mis ojos ya no estaba contigo $(7,7,11)$; también regenerado $(8,2,4)$; abandonado ya el mundo, aún no te servía $(8,5,10) ;$ nuevos hijos $(8,11,27)$; Todo este abismo [Agustín no habla aquí de un abismo, sino de su situación] $(9,1,1)$; el Señor ha glorificado ya a su santo $(9,4,9)$; aun lleno de ti ... Ya no escondo mis heridas $(10,28,39)$; remedio del alma $(10,35,55)$.

3) Hemos detectado asimismo un número significativo de frases que, a nuestro parecer, no reproducen el contenido del texto latino. El número lo podríamos aumentar, pero nos hemos limitado a algunas más llamativas: Por buscarme a mí mismo y los deleites... no en él sino en las demás criaturas... [= por buscar los deleites no en Él, sino en sus criaturas, en mí mismo y en las demás] $(1,20,31)$; acerca de los cuales (elementos) aun a los filósofos que hablan bien de ellos debi yo tomarles la delantera por amor tuyo [= más allá de los cuales debí ir yo por amor tuyo] $(3,6,10)$; o porque se tolera hacer tras la comida lo que se prohíbe antes de ella [= se tolera hacer en los establos lo que se prohíbe delante de la mesa] $(3,7,13)$; creer que el higo llora cuando se le arranca y llora también, como a su 
madre, al árbol con lágrimas de leche [= creer que, cuando se le coge del árbol, el higo y su madre, la higuera, lloran lágrimas de leche] $(3,10,18)$; se alimenta de vientos [ = alimenta vientos] $(4,2,3)$; no abusar de tu indulgencia para con la libertad de pecar [= no usar indebidamente de tu indulgencia como licencia para pecar] $(4,3,4) ;$... que aún no mantenía la comunidad de los fieles, por ser casi un adolescente [ $=$ que, en cuanto adolescente, no poseía bien arraigada la fe] $(4,4,7)$; ¿Qué amo en otro que, de no odiarlo en mí mismo, no lo detestaría...? [= que, si no lo odiase al mismo tiempo...] $(4,14,22)$; ... de no alabarlo, esos mismos lo vituperarían, y vituperándolo y menospreciándolo, narrarían las mismas cosas, sólo que yo... [= porque si esas mismas personas, en vez de alabarlo, lo hubiesen criticado, y al criticarlo y despreciarlo, hubiesen dicho de él exactamente las mismas cosas, no me hubiese entusiasmado por él...] $(4,14,23)$; no preservé mi vigor para tu (de Dios) custodia [= no guardé mi fortaleza en ti] $(4,16,30)$; entre nosotros [= entre ellos -los maniqueos-] $(5,3,3)$; por cuánto tiempo se ocultarían (el sol y la luna) [= si iban a ser -los eclipses- parciales o totales] $(5,3,4)$; departir juntos la preocupación por mis cuestiones [= departir juntos las cuestiones que me preocupaban] $(5,6,11)$; a él era conducido por ti sin yo saberlo, para que yo me condujera a ti, a sabiendas [ = para que él me condujera a ti, sabiéndolo yo] $(5,13,23)$; ¿Es que no me hiciste tú y estableciste diferenciarme al hacerme más sabio que los cuadrúpedos y las aves del cielo? [= ¿acaso no me habías creado y distinguido de los cuadrúpedos y hecho más sabio que las aves del cielo?] $(6,1,1)$; Estando con él [= estando allí] $(6,3,3)$; burlarse con temeraria arrogancia de la credulidad de la ciencia [= que con su temeraria promesa de ciencia se burlaban de la fe...] $(6,5,7) ; . .$. cuántas cosas sobre... ciudades que jamás había visto, o acerca de mis amigos, sobre médicos, sobre tantos y tantos hombres, los cuales... [= sobre cosas oídas a amigos, a médicos, a gente de todo tipo] $(6,5,7)$; pero no quedaba posibilidad alguna de amonestarlo y apartarlo con alguna prohibición, a causa de nuestra buena amistad y por las leyes mismas de enseñanza [= pero ni por razón de amistad, ni por razón de magisterio tenía oportunidad de amonestarlo o de actuar para apartarlo...] (6,7,11); ¿Quién me hizo? ¿Es que mi Dios no sólo es bueno, sino el bien mismo? [ ¿QQuién me hizo? ¿Acaso no me hizo mi Dios que no sólo es bueno, sino el bien mismo?] $(7,3,5)$; se adhería fija a mi corazón en la Iglesia católica, una fe... [= estaba adherida a mi corazón la fe que la Iglesia católica tiene en tu Hijo...] $(7,5,7)$;... no como en un lugar, sino porque tú las mantienes todas con tu mano como verdad, con la fuerza de la verdad... [ = no como en un lugar, sino en cuanto tienes todo en la verdad 
como en una mano...] $(7,15,21) ;$... incapaz de tomar, por ser alimento mezclado a la carne [= y mezclando con la carne el alimento que era incapaz de tomar...] $(7,18,24) ; . .$. y que aquella carne no se unió a tu Verbo sino a un alma y una mente humana [= y que aquella carne no se unió a tu Verbo sin un alma y una inteligencia humana] $(7,19,25)$; $Y$ una cosa es ver la patria de la paz de lejos... o no hallar el camino que conduce a ella, o intentarlo en vano... [ = una cosa es ver la patria de la paz de lejos... y no hallar el camino que conduce a ella, e intentar en vano...] $(7,21,27)$; de hacerse un fiel de tu Cristo [ = de hacerse siervo de tu Cristo] $(8,2,3)$; por su predicación [per eius militiam] $(8,4,9)$; Y ese enemigo esclaviza a los soberbios con el nombre de nobleza, y... a otros muchos con el nombre de autoridad [= con el prestigio de la nobleza y ... a muchos más gracias al prestigio de su autoridad $](8,4,9)$; asesorar por tres veces al magistrado [= ejercer por tres veces una asesoría] $(8,6,13) ; \ldots$ tanto más densas se hicieron sus tinieblas [ $=$ se hicieron ellos tinieblas más densas] $(8,10,22) ; \ldots$ por su familiaridad no lo pone $[=$ no lo depone $](8,11,24)$.

... no volver a vender mi palabra [ $=$ no hacerme venal $](9,2,2)$; recordamos en su momento [= fue evocado en un momento] $(9,1,1) ; \ldots$ de donde solía preguntarme [ = acerca de lo cual] $(9,3,6)$; Y al leer esto, decía al exterior lo que reconocía en mi interior, ni deseaba multiplicarme... [= y exclamaba leyendo estas cosas fuera y comprendiéndolas dentro] $(9,4,10) ;$... y movió los ojos [= lo llevó -el pañuelo- a los ojos] $(9,7,16)$; desaparecidos ya su padre, sus madre y sus nodrizas [= estando ausentes padre, madre y nodrizas...] $(9,8,18)$; recuerden... a quienes, durante esta luz pasajera, fueron mis padres y hermanos, cobijados bajo tu amparo, como madre, y conciudadanos míos [= a quienes fueron mis padres en esta luz pasajera, y mis hermanos, bajo ti, Padre, en la Iglesia Católica, y mis conciudadanos...] (9,13,37); la ilusión de aquella imagen de mi alma [= sobre mi alma] $(10,30,41)$; impuso a sus nietos, descendientes de José, las manos místicamente extendidas, en cuanto padre suyo; no los corregía desde fuera, sino tal como los reconocía él mismo desde dentro [= impuso a sus nietos, nacidos de José, las manos misteriosamente cruzadas. No como el padre de ellos buscaba orientarlas exteriormente, sino como él mismo veía interiormente] $(10,34,52)$; Y yo veo que tú prefieres sanar enseguida mis heridas a que no me sean infligidas [= en cuanto a mis heridas, soy más sensible a que tú me las curas enseguida que a no recibirlas] $(10,39,64)$; para que, al no estar recubierto de la mortalidad de la carne, pueda manifestarse en lugar del inmortal [= puesto que... se presenta como inmortal] $(10,42,67) ;$ ¿Dónde está el cielo que no vemos, para el que (=comparado 
con el cual) todo cuanto vemos es tierra? $(12,2,2) ; . .$. por todas las cosas que no bastaría con sólo decirlas [= que no es capaz de decirlas todas] $(12,6,6)$; sino por siempre el mismo y lo mismo [= sed idipsum et idipsum et idipsum [ = no ha captado la referencia trinitaria-] $(12,7,7)$; ¿Y quién podrá explicármelo sino quien devanea...? ¿Quién sino uno así me dirá si, menguada y consumida toda especie... podría ella producir los vaivenes de los tiempos? [ = ¿y quien sino uno que devanea... quién sino un tal puede sostener que...?] $(12,11,14)$; no declina ni de ti ni hacia sí [= ni de sí] $(12,15,19) ;$ ¿... cuál propugnáis que sea falsa? ¿Quizá por tratarse de una materia informe...? (= ¿qué sostenéis que es falso? ¿Acaso que había una materia informe...? $(12,15,22)$; Y bien sé de qué dos mandamientos... [= nuestro maestro conoce de qué dos mandamientos...] $(12,18,27)$; celsitudo... requies: elevador... descanso $(12,26,36)$; les ocurre en estas cosas como a los animales aún pequeños, que mientras se gesta... su propia debilidad... crece para la salvación su fe, por la que creen y mantienen que Dios ha hecho... [¡los animales creen!] (12,27,37); las formas de las cosas se sirven de los tiempos [= dan origen a los tiempos] $(12,29,40) ; \mathrm{Y}$ si no es confesándotelo, lo ignoro $[=\mathrm{y}$ si no te lo confieso, es que lo ignoro] $(12,30,41)$; porque ni tu informidad te hubiera agradado si la luz no se hiciera $[=$ si no se hubiera hecho luz, no existiendo, sino...] $(13,3,4)$; Dame a ti mismo, y vuélvete a mí $[=$ devuélvete a mí] $(13,8,9)$; ni como vivientes por el poder de un hombre superior [= por la autoridad (moral)] $(13,22,32)$.

4) Por lo que se refiere a palabras concretas, son también frecuentes los casos en que no se traducen fielmente, o no se recogen sus matices. Ejemplos: Silvescere: bruto salvaje [= convertirse en una selva] $(2,1,1)$; perversus/a/um, perverti: suele interpretar la palabra en sentido moral (perverso/a), cuando las más de las veces lo tiene psicológico o incluso físico -extraviado, fuera de camino- (passim); tanta: tantas [= tan grandes] $(2,7,15)$; implicari: sanar [= implicar, enredadar] $(2,7,15)$; fastidiosior: más tedio [más hastío] $(3,1,1)$; parvulis fidelibus: fieles noveles [= parvus en sentido de formación religiosa, no cronológico] $(4,15,25)$; reficere: reconfortar [= rehacer, re-crear] $(5,2,2)$; vultus congruus: rostro agraciado [= gesto apropiado] $(5,6,10)$; veneram: venido [= ido (a Roma, pues escribe en Hipona)] $(5,12,22)$; puer; niño [= esclavo, junto a dominus] (6.9.15;); nosti (conociste) [=conoces] $(7,4,6)$; proicientis, desprecia [= echa fuera] $(7,16,22) ;$ phantasmata: fantasmas [así traducida la palabra latina, el lector ordinario difícilmente entenderá lo que quiere decir el santo] $(7,17,23$; passim); infirmus: enfermo [= débil] $(7,20,26)$; laborare: trabajar [= trabajar con fatiga, fatigarse] $(7,21,27$ y passim $)$; aedes: edificios [= edificio] 
$(8,8,19)$; inolitum: inoculado [= sólito (inolitum/insolitum)] $(8,11,25)$; turpitudo: vileza [ = torpeza] $(8,12,28)$; claritas: claridad [= gloria] $(9,1,1) ;$ per litteras: por cartas [= por carta] $(9,5,13)$; parturit/parturiit: concibe/concibió [= parió/parió con dolor] $(9,8,17)$; domina minore: señorita suya de menor edad [= ama de menor edad] $(9,8,18)$; pius: piadoso [= buen hijo] $(9,12,30)$; sensifico: la percibo por el sentido (= hago que sienta) $(10,7,11)$; memini: recordé $[=$ recuerdo] $(10,25,36)$; intueri: intuir $[=$ ver, contemplar $)$ $(11,18,24 ; 13,3,4)$; novit: anhela [= conoce] $(13,10,11)$.

A lo dicho cabe añadir la variedad de significados asignada a palabras con uno muy específico, como es el caso de flagitium y facinus $(1,16,25 ; 3,2,3 ; 3,8,15 ; 3,9,18 ; 4,15,25)$; el traducir diversamente la misma palabra en textos que, por ser paralelos, reclaman idéntica traducción: cogitabam: imaginaba/pensaba $(12,6,6)$; bestiae/pecora: bestias/brutos y fieras/bestias $(13,21,30-31)$.

5) La puntuación es esencial en un texto, porque de ella depende en buena medida su sentido. Pero en los textos antiguos constituye a menudo un problema dado que se nos han trasmitido sin ella y queda a la pericia del editor el elegir entre una $u$ otra. El traductor de la obra ha optado con frecuencia por una puntuación que no nos parece acertada y, más de una vez, crea problemas de inteligencia del texto. Dos ejemplos: Un incorrecto uso de los guiones hace una frase gramaticalmente ininteligible (último punto de 1,9,15), o no refleja bien el sentir del autor: ... ira de la que también nosotros fuimos hijos, en otro tiempo. Tinieblas, cuyos residuos... [= ira de la que también fuimos hijos nosotros, que en otro tiempo fuimos tinieblas, cuyos residuos...] $(13,14,15)$.

6) Es sabido que el latín hace un uso más que abundante de las conjunciones. Es normal que al inicio de cada frase aparezca una $u$ otra que señale la relación con la frase anterior, y que en español no siempre es necesario traducir sin que se vea afectado el sentido del texto. Es la opción que toma el traductor. Con todo, las conjunciones tienen su función y hay casos en que no se deben menospreciar en pro de la fidelidad. En conjunto, la traducción que examinamos no presta a las conjunciones toda la atención que merecen. Señalamos algunos datos, con ciertos ejemplos que se podrían multiplicar fácilmente. 1) Deja de traducir conjunciones que aportan un matiz significativo: Et tamen toto orbe... $(9,4,8)$; Quia non est mihi... (10,20,29). 2) Las introduce cuando no existen en el texto latino: «por la humanidad de tu hijo y por el ministerio de tu predicador» $(1,1,1)$, distinguiendo así entre el Hijo de Dios y el anunciador. 3) Asigna a unas el significado de otras: traduce una adversativa por una comparativa: sed 
por como $(4,14,22)$; una causal por una adversativa: enim por sin embargo $(7,20,26 ; 10,33,49)$; una adversativa por una causal: sed por porque $(10,34,53)$; una ilativa con valor adversativo: itaque por "por el contrario" $(10,42,67)$; una adversativa por una causal: tamen por pues $(11,18,24)$; Interpreta como causales partículas completivas: quod ab illa esset: porque de ella toda otra sustancia procede [= que toda otra sustancia procede de ella] $(8,1,1)$; Respondetur mihi quoniam: y se me responde: porque [= y se me responde que...] $(13,31,46)$, etc.

7) Otros datos de menor importancia; a) recurso frecuente a cuantificadores que no están en el texto: gran esperanza $(2,3,8)$; tan humilde $(7,18,24)$; mucho más débil $(8,2,2)$; tan horrendos $(9,2,2)$; gran medida $(10,37,60)$. b) interpreta moralmente un concepto metafísico: aquello por lo que obraba el defecto $(2,4,9)$. c) error en el adjetivo posesivo: su propia imagen [no de Mónica, sino de Dios]; $(1,11,18) ; m i$ [= su] gran esperanza $(2,3,8)$, etc.

8) Los datos sobre la edad no son fieles. Al respecto hay que hacer tres consideraciones: 1) El traductor no tiene en cuenta que, cuando el latín usa el numeral para indicar la edad, en español ha de rebajarse una cifra, porque entonces se indica el año que se encuentra viviendo la persona, no el número de años «cumplidos», agotados. En consecuencia, cuando el santo escribe: en el año décimo noveno de mi vida, hay que verterlo: a mis 18 años. No tener en cuenta este dato lleva al traductor a cometer continuamente errores en la indicación de la edad $(3,4,7 ; 4,1,1$; $4,16,28 ; 5,3,3 ; 6,11,18 ; 7,1,1 ; 8,7,17 ; 9,11,28)$. 2) Tampoco tiene en cuenta que las distintas etapas de la vida no siempre coinciden cronológicamente con las nuestras. La adolescencia para los romanos duraba mucho más para nosotros (en el libro sexto aún habla Agustín de su adolescencia), y la juventud comenzaba más tarde (el santo sólo comienza a hablar de la suya en el libro séptimo, ya con 30 años). Esto le lleva a errores. Uno claro: cuando en la introducción sostiene que fue en Madaura, y no en Cartago, donde asistió a las celebraciones cultuales de la diosa Cibeles por la única razón de que en La Ciudad de Dios 2,4 la coloca en su adolescencia (p. 37). 3) Al indicar la edad, en español hablamos de años «cumplidos». En consecuencia, para ser precisos hay que aplicar el criterio a la hora de indicar los años: cuando Agustín se convierte en agosto del 386, tenía 31 años (los 32 los cumplía en noviembre); por la misma razón, ha de decirse que se bautizó a los 32 años, no a los 33 (pp. 315 y 354). 
B. El compromiso con el lector: claridad y belleza. El traductor declara que no ha querido sucumbir a la modernización despiadada e incolora -y evidentemente no ha sucumbido-, sino que ha intentado captar el sabor originario y personal del lenguaje de Agustín -pero en el intento ha sacrificado en cierta medida la claridad y la belleza-. Volviendo a la imagen utilizada anteriormente, es innegable que el recipiente original es irrepetible y que lo más a que puede aspirar el traductor es a que el nuevo no desmerezca a su lado. La impresión de este lector es que A. U. J. no lo ha conseguido. En cuanto a la claridad, es cierto que son muchas las páginas en que la lectura fluye ágil; pero también hay otras muchas que requieren máxima concentración e incluso una doble lectura, si se quiere entender el texto. En cuanto a la belleza, es inseparable de un uso correcto de la gramática, que no siempre percibimos. A continuación aportamos los datos con que avalamos nuestro juicio.

1) Es innegable que, con frecuencia, el texto agustiniano es difícil de verter al español. En ello tiene que ver muchas veces la naturaleza de la lengua latina que permite párrafos con un sinfín de coordinaciones y subordinaciones; otras con la complejidad del tema («al hablar de maniqueos la expresión de Agustín se oscurece» [p. 261]) y otras todavía con el pasado retórico de Agustín. El traductor ha de mostrar su arte en el hacer inteligible esos textos difíciles. Lamentablemente no consideramos que sea el caso en la traducción que tenemos entre manos. En ello ha influido, creemos, la puntuación adoptada para el texto latino, un inadecuado trato con los verbos, una incorrecta construcción gramatical y, a veces, una distracción del traductor, como cuando afirma erróneamente que Agustín deja una frase inconclusa $(13,34,49 ;$ p. 554, n. 140). Según indicamos ya, de principio a fin el lector topa con pasajes oscuros que requieren un máximo de atención para captar su sentido, cuando es posible. En efecto, hay frases que, de hecho, resultan ininteligibles. A la ya indicada $(1,9,15)$, añadimos esta otra: Y más aún que mis palabras... tono de mi voz [falta el verbo, y el de la frase anterior no sirve] $(8,8,19)$. Otras frases no llegan a ese nivel, pero tampoco son tan claras como sería de desear. Ejemplos no faltan (para no aumentar las páginas, indicamos sólo el inicio y el fin del período que consideramos oscuro): Se retrasó, pues, mi purificación... más peligrosa $(1,11,17)$; en realidad huyeron... de tu rigor $(5,2,2)$; más aborrecía... de dinero $(5,12,22)$; un tiempo liberado... difíciles $(6,3,3)$; con cuyos beneficios muchos le estaban obligados o sometidos por temor $(6,10,16)$; tengo muchos amigos... podría obtener $(6,11,19)$; pero en lo inferior... los levantara $(7,18,24) ; \ldots$ de tu gracia... te posea $(7,21,27) ; . .$. costumbre arraigada... 
suspirar por ella $(8,3,7)$; el único que... tiempos de cada una $(8,3,8) ; \ldots$ bien querría..., oirían... de mi alma $(9,4,8)$; si pudieran traer... mostrará el bien? $(9,4,10) ; \ldots$ para que oigamos... oigámosle... de inferior naturaleza $(9,11,25)$; y de un modo veo... he pensado $(10,13,20)$; Pero cuando el pecador... que es alabado $(12,36,59)$; Y por lo de... mencionar los días $(12,13,16) ;$ Todo el párrafo $(12,15,20)$. Pero como todas ellas... iluminación de la Sabiduría? $(12,17,25)$; No es igual vivir que vivir sabiamente, pues de lo contrario, conocería de modo inmutable $(13,2,3) ; \ldots$ porque le veremos tal cual es, como nuestro es, Señor, un ver que aún no tenemos $(13,15,18)$; Pues estas cosas... cuerpo $(13,20,27)$.

2) Hablamos antes del inadecuado trato con los verbos. $\mathrm{Al}$ respecto cabe anotar: a) Hay casos en que el latín pide determinados modos o tiempos verbales que no se corresponden con el español. Pues bien, el traductor no siempre actúa en coherencia con ello. De ahí que muchas frases no fluyan en español: quizá alguien dijera que falté en que... pudiera sentarme $(9,2,4)$; Manifestaré... no quién haya sido, sino quien soy ya $(10,4,6)$; nada encuentro de ti que no recordara desde que te conocí $(10,44,35)$; Pero cuando hallare algo en esas tres cosas y lo dijera, no piense... $(13,11,12)$; etc. b) Hay tiempos latinos como el pretérito perfecto de indicativo que en castellano admiten dos traducciones según el contexto: el indefinido (una acción considerada sólo en su condición de pasada) o el pretérito perfecto (una acción del pasado considerada en cuanto que perdura en el presente). El traductor a menudo hace caso omiso de esa diferencia: los lugares en los que estuve [= he estado] $(10,16,25)$. c) A veces falla la correlación de tiempos: no nos era dado [= había sido dado: erat datus] porque... aún no había sido glorificado $(9,4,9)$; Tú los liberarás [= liberas], porque caen en la trampa. Tú no cesarás [= cesas] de librarlos, porque... $(10,34,52)$; pero yo... soy cazado, y tú ... me librarás (= libras), a veces sin yo notarlo, porque había caído de forma más breve, pero otras con gran dolor, porque ya estaba apegado $(10,34,53)$; de no haberse hecho carne... hubiéramos podido pensar que tu Verbo se mantendría (= se había mantenido) alejado $(10,43,69)$; etc.

3) Hablamos asimismo de una incorrecta construcción gramatical (inseparable a menudo del uso incorrecto de los tiempos verbales). Los ejemplos también abundan: al considerar yo cuántas cosas creía sin haberlas visto, ni había estado presente cuando se hicieron... $(6,5,7)$; carbones abrasadores con qué cauterizar ... y la sanaras $(6,7,12)$; pues si son y no pueden corromperse, serían mejores... $(7,12,18)$; me persuaden hacer... de lo que las cosas reales no logran $(10,30,41)$; Pero dicen... nosotros decimos 
[el texto se hace oscuro al no señalar las palabras textuales] $(12,14,17)$; cuando la Verdad me dice: que su sustancia no varía..., ni que su voluntad sea diversa... $(12,15,18)$; hubiera deseado, si yo fuera... $(12,26,36)$; a menos que se convierta... y se hiciera... $(13,5,6)$.

4) El traductor no capta las imágenes o, al menos, no las reproduce. La de la relación esponsal con Dios, al verter fornicatio por pecado o meretrix por pecadora $(1,13,22 ; 4,2,3 ; 5,12,22)$; la del parto, al verter parire por expresar $(1,14,23)$; la de la Escritura como un edificio con entrada pobre y pequeña y hermoso interior $(3,5,9)$; la del animal que se sacude el barro: excussit... et resuiluerunt ... sordes $(6,7,12)$; la de quien, acostado en la cama, no logra conciliar el sueño: yendo y volviendo... [= vueltas y más vueltas... (versa et reversa...)] $(6,16,26)$; la de un asalto a alguien: invado $(8,8,19)$, etc.

5) Otros datos de menor importancia: a) no evita expresiones que pueden entenderse de forma inadecuada: la buena vida [= la vida recta] $(10,37,60)$. b) Le falta uniformidad en la traducción de sentencias o sintagmas bien definidos como Da quod iubes... $(10,29,40 ; 10,31,45)$ o concupiscentia oculorum $(10,30,41 ; 10,35,54)$; c) A veces cae en una literalidad extrema: si arranqué un cabello $(8,8,20)$; d) uso frecuente de la construcción con artículo y posesivo en vez de hacerlo con sólo el posesivo: la misericordia tuya $(10,24,35)$; la buena voluntad tuya $(13,9,10)$, etc. e) Al no respetar la "estructura" de la frase no expresa bien su sentido: para confesar todo esto no sólo ante ti en secreto júbilo, con temblor, con oculto pesar, con esperanza... [= para que me confiese ante ti con gozo secreto, mezclado con temblor, y con secreta tristeza, unida a esperanza...] $(10,4,6)$; f) Reproducir de alguna manera determinados juegos de palabras de la obra es realmente difícil y lograrlo sería un gran éxito. Éxito que no acompañó al traductor, por ejemplo, en los juegos realizados con compuestos del verbo vertor $(3,3,6 ; 4,16,31)$.

6. En general anotamos: a) un uso que creemos excesivo del pronombre personal, sobre todo de primera persona. b) Un uso más excesivo aún de la voz pasiva, preferida a menudo por el latín, pero no por el español. c) Cierta predilección por dejar el verbo al final del período, imitando así al latín.

7. Señalamos atgunos descuidos: tu vida [= tu camino (vitae/viae)] $(8,1,1)$; cosas visibles [ = cosas buenas] $(8,2,2)$; de mi humanidad [= de mi mortalidad] $(10,4,6:)$; infinitud [= informidad] $(12,22,31)$; vivir [= oír] $12,21,30)$; para entender de algún modo... $(9,10,33)$; lo que fuera de ella está disperso [= dentro de ella] (p. 394, n. 31). 
8) Es difícil que en una obra de muchas páginas no aparezcan como indeseables gorronas, las erratas. Aunque no muchas, sí hemos detectado algunas: supesto [= supuesto] (p. 149); las [= los] compadeces $(3,2,3)$; entoces $(4,4,7)$; constumbre $(8,11,26)$; los que [= lo que] $(9,5,13)$; simpre (p. $365)$; hacen míseros (= hace) $(10,23,33)$; estinam [ = estiman] $(10,37,61)$; del [= de la] $(12,21,30)$; lo (= la) buscaba $(13,5,6)$; tanpoco $(13,23,33)$. Citas bíblicas erróneas: 1 Cor 7,25 [= 1 Cor 7,32-33] (p. 159, n.3); Jn 2,16 [=1 Jn 2,16] (p. 411, n. 43).

9) A nivel de ortografía nos han llamado la atención dos datos: a) Que, salvo raras ocasiones, dentro de un parágrafo, prescinde del punto cuando la oración siguiente comienza con el signo de interrogación. Un ejemplo: ... si tú no estuvieras ya en mí ¿O tal vez mejor...? $(1,3,3)$. b) La grafía alhagaba $(5,10,18) ;$; alhago $(10,34,52)$ (en cambio, halagos en 10,33,50).

10) En cuanto al vocabulario, cabe señalar el uso de algunas palabras que no figuran en el diccionario de la R. A. E como ignominado (=nescio quem) $(5,5,8)$ o custode $(6,9,15)$, o palabras fuera de uso, como pescudar $(11,12,14)$.

11) Errores históricos: ubica en s. III el error de Fotino y de Apolinar, aunque a continuación aporte las fechas auténticas (p. 307, n. 49).

Quienes han tenido o tienen experiencia de traducir un texto antiguo saben bien cuán fácil resulta incurrir en uno u otro de los errores aquí señalados. Como bien dice el autor y ya recordamos, «no se agotan tras mil lecturas». No dudo que también en estas páginas se podrá contabilizar más de un error. 